\section{SAT0362 DEPRESSIVE SYMPTOMS ARE ASSOCIATED WITH A GREATER CARDIOVASCULAR RISK IN PATIENTS WITH PSORIATIC ARTHRITIS.}

Gerlando Natalello ${ }^{* 1}$, Enrico De Lorenzis ${ }^{1}$, Dario Bruno ${ }^{1}$, Giacomo Tanti ${ }^{1}$, Maria Rosaria Magurano ${ }^{2}$, Barbara Tolusso ${ }^{3}$, Giusy Peluso ${ }^{3}$, Elisa Gremese ${ }^{13} .{ }^{1}$ Catholic University of the Sacred Heart, Institute of Rheumatology, Rome, Italy; ${ }^{2}$ Fondazione Policlinico Universitario A. Gemelli IRCCS, Department of Psychology, Rome, Italy,; ${ }^{3}$ Fondazione Policlinico Universitario A. Gemelli IRCCS, Department of Rheumatology, Rome, Italy

Background: Cardiovascular (CV) events are the leading cause of death in patients with psoriatic arthritis (PsA) but current cardiovascular risk prevention strategies in these subjects appear to be inadequate. The prevalence of depressive symptoms, even in the absence of a diagnosed depressive disorder, is greater in patients with PsA than in the general population.

Objectives: The objective of the study is to evaluate the association between CV risk factors and depressive symptoms in a cohort of patients with PsA.

Methods: We enrolled consecutive patients with PsA (CASPAR criteria) without a diagnosis of major depression or history of major CV events. The presence of significant depressive symptoms was defined by the Hospital Anxiety and Depression Scale (HADS) for scores â\%» 8 . The subjects were characterized by disease phenotype, duration and activity (according to the DAPSA index) and immunosuppressive, antihypertensive, glucose-, urate- and lipid-lowering therapy. In order to assess the prevalence of traditional CV risk factors, patients were characterized by BMI, waist and hip circumference, blood pressure (BP), smoking habits, physical activity and familiarity for myocardial infarction, lipid, glucose and serum urate. The predicted risk of CV events was calculated by the Framingham Risk Score (FRS), Atherosclerotic Cardiovascular Disease (ASCVD) score and Systematic COronary Risk Evaluation (HeartSCORE) risk charts.

Results: One-hundred patients with PsA were enrolled (males $47.0 \%$, mean age $54.9 \pm 12.5$ years, duration of illness $9.1 \pm 10.6$ years) of which $20.6 \%$ were in remission, $43.3 \%$ in low disease activity, $28.8 \%$ in moderate disease activity and $10.3 \%$ in high disease activity according to DAPSA; $38 \%$ had significant depressive symptoms according to the HADS questionnaire. Patients without depressive symptoms had a higher mean age $(57.8 \pm 12.3 v s 52.1 \pm 12.4$ years, $\mathrm{p}=0.002)$ compared to patients with significant depressive symptoms but were comparable according to M:F ratio, duration and domains of psoriatic disease, PASI, DAPSA and immunosuppressive therapy. The presence of depressive symptoms was associated with a higher prevalence of obesity $(34.2 \% \mathrm{vs} 9.7 \%, \mathrm{p}=0.002)$ and â€œat riskâ€ abdominal circumference (84.2\%vs61.3\%, p=0.015) and hip/waist ratio $(81.6 \% \mathrm{vs} 50.0 \%, \mathrm{p}=0.002)$. Moreover, these patients had more frequently a history of active or previous smoking $(63.2 \%$ vs.40.3\%, $\mathrm{p}=0.027$ ) but did not differ according to lifestyle, BP, antihypertensive therapy or familiarity with myocardial infarction compared to patients without depressive symptoms. With regard to the metabolic profile, patients with and without depressive symptoms did not differ in terms of exposure to lipid- and glucose-lowering drugs and fasting glucose values. However, patients with depressive symptoms had increased atherogenic risk index more frequently $(76.3 \%$ vs $54.8 \%, p=0.046)$ and greater $\mathrm{LDL} / \mathrm{HDL}$ ratio $(2.6 \pm 1.2 \mathrm{vs} 2.1 \pm 0.7, \mathrm{p}=0.017)$ and serum triglycerides values $(135.1 \pm 53.7 \mathrm{mg} / \mathrm{dl}$ vs $108.8 \pm 58.6 \mathrm{mg} / \mathrm{dl}, \mathrm{p}=0.046)$. The estimated risk of cardiovascular events at 10 years for traditional risk factors was greater for patients with depressive symptoms (FRS 16.8 $\pm 12.3 v s 10.4 \pm 6.0, p=0.003$; HeartSCORE 1.9 $\pm 1.5 v s 1.1 \pm 1.0, p=0.011$; ASCVD $11.7 \pm 8.8 v s 7.8 \pm 8.4, p=0.05$ ).

Conclusion: The presence of depressive symptoms is associated with a higher incidence of modifiable CV risk factors and a higher predicted risk of CV events in patients with PsA. Systematic research of depressive symptoms in patients with PsA could contribute to the correct assessment of $\mathrm{CV}$ risk, helping to implement more effective prevention strategies.

Disclosure of Interests: Gerlando Natalello: None declared, Enrico De Lorenzis: None declared, Dario Bruno: None declared, Giacomo Tanti: None declared, Maria Rosaria Magurano: None declared, Barbara Tolusso: None declared, Giusy Peluso: None declared, Elisa Gremese Consultant for: AbbVie, BMS, Celgene, Janssen, Lilly, MSD, Novartis, Sanofi, UCB, Roche, and Pfizer, Speakers bureau: BMS, Speakers bureau: Roche, Speakers bureau: AbbVie, BMS, Celgene, Janssen, Lilly, MSD, Novartis, Sanofi, UCB, Roche, and Pfizer

DOI: 10.1136/annrheumdis-2019-eular.440

\section{SAT0363 \\ ENTHESITIS BUT NOT DACTYLITIS CONTRIBUTES TO BURDEN OF DISEASE IN PSA PATIENTS: DATA FROM THE BEPAS REAL LIFE COHORT}

Kurt de Vlam ${ }^{1}$, Rik Lories ${ }^{1}$, Serge Steinfeld ${ }^{2}$, Filip van den Bosch ${ }^{3}$, Adrien Nzeusseu Toukap ${ }^{4}$, Hermine Leroi ${ }^{5}$, BEPAS working group . ${ }^{1}$ University Hospitals Leuven, Rheumatology, Leuven, Belgium; ${ }^{2}$ Clinique St Jean, Rheumatology, Brussels, Belgium; ${ }^{3}$ University Hospital Gent, Rheumatology, Gent, Belgium; ${ }^{4}$ UCL St Luc, Rheumatology, Brussels, Belgium; ${ }^{5}$ MSD Belgium, Medical Affairs Immunology, Brussels, Belgium

Background: Psoriatic arthritis (PsA) significantly impacts physical function and quality of life. Limited data are available to specifically evaluate the impact of the different disease domains such as arthritis, axial involvement, skin disease, enthesitis and dactylitis. The BEPAS cohort, a prospective daily life cohort of PsA patients allows to study the impact of enthesitis and dactylitis on disease activity, disability and quality of life in PsA patients.

Objectives: 1) to measure the impact of enthesitis and dactylitis on health-related quality of life in PsA patients in Belgium.

Methods: At the inclusion visit, a cross-sectional analysis of dactylitis and enthesitis was performed among 462 patients from the BEPAS cohort and impact of enthesitis and/or dactylitis was studied. Patients were evaluated for the demographics, clinical disease manifestations, disability, dis ease global assessment and inflammatory markers at inclusion Differences of tested variables between patients with and without dactylitis and/or enthesitis were evaluated by T-test or Chi -square testing.

Results: 462 patients $(273$ males and 189 females) with a mean disease duration of 8.53 years (SD: 9.25yrs) were recruited in 17 BEPAS centers from December 2012 to July 2014. 111 patients had enthesitis and 63 patients had dactylitis at inclusion. 17 patients had both enthesitis and dactylitis. Results are summarized in the table below:

Conclusion: Enthesitis has a larger impact on Quality of Life and Health Status than dactylitis in PsA. Patients with enthesitis and dactylitis have higher joint scores but not higher markers of systemic inflammation than those without.

Acknowledgement: This study is financially supported by MSD Belgium Disclosure of Interests: Kurt de Vlam Consultant for: Pfizer Inc, Consultant for: Johnson \& Johnson, Rik Lories Consultant for: Abbvie, Celgene, Eli-Lilly, Janssen, Merck, Novartis, Pfizer, UCB, Serge Steinfeld: None declared, Filip van den Bosch Consultant for: AbbVie, BMS, Galapagos, Janssen, Lilly, Merck, Novartis, Pfizer and UCB, Speakers bureau: AbbVie, BMS, Janssen, Lilly, Merck, Novartis, Pfizer and UCB., Adrien Nzeusseu Toukap: None declared, Hermine Leroi Employee of: HL is a employee of MSD Belgium

\begin{tabular}{|c|c|c|c|c|}
\hline & $\begin{array}{l}\text { Enthesitis } \\
(n=111)\end{array}$ & $\begin{array}{c}\text { No Enthesitis } \\
\quad(n=351)\end{array}$ & $\begin{array}{c}\text { Dactylitis } \\
(n=63)\end{array}$ & $\begin{array}{c}\text { No Dactylitis } \\
(\mathrm{n}=399)\end{array}$ \\
\hline & Mean (SD) & Mean (SD) & Mean (SD) & Mean (SD) \\
\hline Disease duration & $7.97(8.87)$ & $8.71(9.37)$ & $5.12(6.35)$ & $9.07(9.53)^{\star}$ \\
\hline BMI & $27.89(4.94)$ & $27.30(4.95)$ & $27.35(4.97)$ & $27.47(4.94)$ \\
\hline TJ78 & $7.71(10.34)$ & 23.49)§ & $8.57(11.99)$ & $3.36(5.89) \S$ \\
\hline SJ76 & $2.94(4.40)$ & $1.86(4.51)^{\star}$ & $6.33(7.42)$ & $1.45(3.41) \S$ \\
\hline BSA & $5.11(13.22)$ & $2.85(6.67)^{\star}$ & $3.18(5.74)$ & $3.44(9.20)$ \\
\hline CRP & $4.88(6.06)$ & $6.17(11.14)$ & $6.04(6.16)$ & $5.82(10.64)$ \\
\hline PTGAVAS & 47.04 (19.88) & $32.92(23.49) \S$ & $42.54(26.78)$ & $35.33(22.63)^{\star}$ \\
\hline PGAVAS & $34.88(21.23)$ & $21.28(20.12) \S$ & $39.2(23.63)$ & $22.16(19.79) \S$ \\
\hline DAS28CRP & $3.42(1.14)$ & $2.66(1.06) \S$ & $3.55(1.39)$ & $2.73(1.03) \S$ \\
\hline DAPSA/DAREA & 24.11(15.66) & $17.27(16.66)^{\star}$ & $19.03(16.65)$ & $17.17(15.39) \S$ \\
\hline MDA & 9/111 (8\%) & 164/349 (47\%)§ & 10/63 (16\%) & $163 / 397(41 \%) \S$ \\
\hline $\mathrm{HAQ}$ & $0.93(0.60)$ & $0.65(0.63) \S$ & $0.82(0.69)$ & $0.70(0.62)$ \\
\hline $\begin{array}{l}\text { HAQ score status } \\
(<0,3)\end{array}$ & 16/111 (14\%) & 135/359 (38\%)§ & 19/62 (30\%) & 132/399 (33\%) \\
\hline PSAQOL & $8.20(5.25)$ & $5.17(5.27) \S$ & $7.24(6.46)$ & $5.70(5.22)^{\star}$ \\
\hline SF36 phys funct & $51.56(25.85)$ & $65.39(27.13) \S$ & $57.84(31.56)$ & $62.69(26.73$ \\
\hline SF36 role-physical & 44.15(27.28) & $59.70(29.86) \S$ & $51.81(33.90)$ & $56.62(29.31)$ \\
\hline $\begin{array}{l}\text { SF36 role- } \\
\text { emotional }\end{array}$ & $57.63(31.98)$ & $72.22(25.33) \S$ & $65.18(35.37)$ & $69.30(30.40)$ \\
\hline SF36 vitality & $40.51(19.03)$ & $54.58(21.91) \S$ & $50.06(24.70)$ & $51.37(21.67)$ \\
\hline $\begin{array}{l}\text { SF36 mental } \\
\text { health }\end{array}$ & $53.56(21.53)$ & $66.41(20.73) \S$ & $62.06(24.17)$ & $63.51(21.22)$ \\
\hline SF36 social funct & 60.69(25.16) & $72.41(25.33) \S$ & 65.72(26.19) & $70.18(25.66)$ \\
\hline SF36 bodily pain & $38.70(19.59$ & $54.00(23.92) \S$ & $45.19(24.07)$ & $51.12(23.75)$ \\
\hline $\begin{array}{l}\text { SF36 general } \\
\text { health }\end{array}$ & $40.42(18.33)$ & $50.14(21.10) \S$ & 48.72(21.68) & $47.69(20.76)$ \\
\hline $\begin{array}{l}\text { SF36 Phys Comp } \\
\text { Sum }\end{array}$ & $35.88(8.64)$ & $41.32(10.42) \S$ & $38.14(10.25)$ & $40.33(10.27$ \\
\hline $\begin{array}{l}\text { SF36 Ment Comp } \\
\text { Sum }\end{array}$ & $39.49(12.80)$ & $46.44(12.77) \S$ & $43.60(14.71)$ & $45.00(12.84)$ \\
\hline
\end{tabular}

${ }^{{ }^{*} \mathrm{p}<0.05, \S p<0.001}$ 


SAT0364

EFFECT OF ACHIEVING DAPSA-LDA ON THE PROGRESSION OF BONE EROSION AND ENTHESIOPHYTES IN PATIENTS WITH PSORIATIC ARTHRITIS: A LONGITUDINAL HR-PQCT STUDY

WU Dongze ${ }^{1}$, James F. Griffith ${ }^{2}$, Steven H.M. Lam ${ }^{1}$, Priscilla C. Wong ${ }^{1}$, Lin Shi ${ }^{3}$, Edmund K. LI ${ }^{1}$, Isaac T. Cheng ${ }^{1}$, K. LI Tena ${ }^{1}$, Vivian W. Hung ${ }^{4}$, Ling Qin ${ }^{4}$, LaiShan Tam ${ }^{1} .{ }^{1}$ The Prince of Wales Hospital, The Chinese University of Hong Kong, Department of Medicine and Therapeutics, Hong Kong, China; ${ }^{2}$ The Prince of Wales Hospital, The Chinese University of Hong Kong, Department of Imaging and Interventional Radiology, Hong Kong, China; ${ }^{3}$ The Prince of Wales Hospital, The Chinese University of Hong Kong, Research Centre for Medical Image Computing, Department of Imaging and Interventional Radiology, Hong Kong, China; ${ }^{4}$ The Chinese University of Hong Kong, Bone Quality and Health Centre, Department of Orthopaedics and Traumatology, Hong Kong, Hong Kong (SAR)

Background: Psoriatic arthritis (PsA) is characterized by structural bone damage with bone erosions and enthesiophytes. Whether achieving low disease activity (LDA) according to Disease Activity in PSoriatic Arthritis (DAPSA-LDA) limits progression of structural bone damage, as assessed by high resolution-peripheral quantitative computed tomography (HRpQCT), is uncertain.

Objectives: To investigate the progression of structural bone abnormalities at the metacarpal head in patients with PsA over a 5-year period.

Methods: HR-pQCT examination was were performed in 60 PsA patients at baseline and after 5 years. Baseline-indexed image registration and slice matching were performed to acquire precisely matched baseline and follow-up volumes of interest (VOI) at the 2nd and 3rd metacarpal heads ( $\mathrm{MCH} 2$ \& 3). A semi-automated method was used to calculate bone erosion and enthesiophyte volume [1]. Erosion and enthesiophyte progression was defined as change exceeding the smallest detectable change (SDC). The primary objective of this study was to investigate the degree of bone erosion and enthesiophyte progression in PsA patients receiving routine care. Secondary objectives were to compare changes in bone erosion and enthesiophyte volume between patients who 1) received (TNFi group) or did not receive TNF inhibitor (non-TNFi group); 2) achieved or did not achieve sustained DAPSA-LDA(sDAPSA-LDA) at both baseline and 5-year.

Results: A total of 108 bone erosions and 99 enthesiophytes were detected at baseline. Three new bone erosions and no new enthesio-
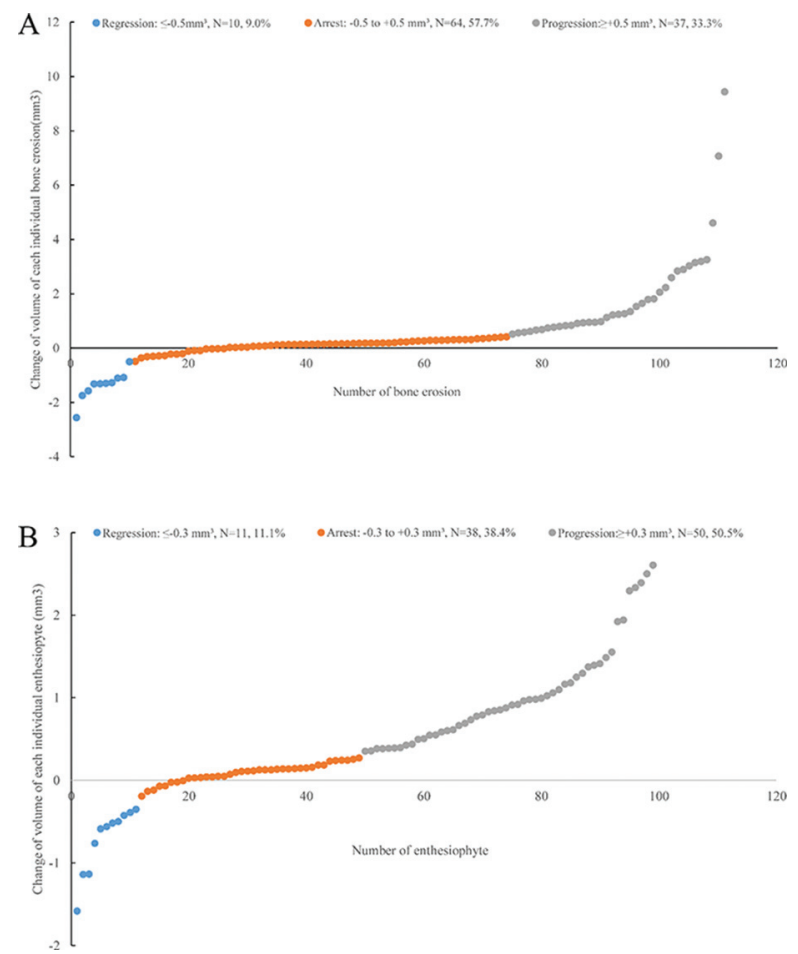

Figure 1. Probability plot of each individual bone erosion and enthesiophyte phytes were evident at 5 years. Mean $( \pm S D)$ individual bone erosion $\left(4.23 \pm 4.15 \mathrm{~mm}^{3}\right)$ and enthesiophyte $\left(3.39 \pm 2.30 \mathrm{~mm}^{3}\right)$ volume at baseline increased significantly $\left(0.58 \pm 1.50 \mathrm{~mm}^{3}, \quad \mathrm{p}<0.001\right.$ for bone erosion; 0.47 $\pm 0.76 \mathrm{~mm}^{3}, \quad \mathrm{p}<0.001$ for enthesiophyte volume) over a 5 -year period despite disease modifying anti-rheumatic drug being used in $88.3 \%$ of patients (Figure 1). The total bone erosion $\left(7.83 \pm 7.41 \mathrm{~mm}^{3}\right)$ and enthesiophyte volume $\left(5.59 \pm 5.46 \mathrm{~mm}^{3}\right)$ per patient also increased by $1.07 \pm 2.16$ $\mathrm{mm}^{3}(\mathrm{p}<0.001)$ and $0.78 \pm 1.11 \mathrm{~mm}^{3}(\mathrm{p}=0.001)$ respectively. 14 patients received TNFi throughout the 5 -year period. Comparable changes in bone erosion and enthesiophyte volume were found between the TNFi and the non-TNFi groups. After 5 years, $26(43 \%)$ patients achieved sDAPSALDA. Less erosion progression (12/51 [23.5\%] vs 25/60 [41.7\%], $\mathrm{P}=0.047)$ was observed those who did rather than did not achieve sDAPSA-LDA Similarly, enthesiophyte volume change $\left(0.28 \pm 0.67\right.$ vs $0.61 \pm 0.80 \mathrm{~mm}^{3}$ $\mathrm{P}=0.048)$ and total enthesiophyte volume change $(0.42 \pm 0.69$ vs $1.05 \pm 1.29$ $\left.\mathrm{mm}^{3} ; \mathrm{P}=0.019\right)$ were lower in those who did rather than did not achieve SDAPSA-LDA.

Conclusion: Once DAPSA-LDA is achieved, it should be maintained for a long period so as to minimize progression of structural bone damage in patients with PsA.

\section{REFERENCE}

[1] EULAR 2018 (OP0132) \& ACR 2018 (865)

Disclosure of Interests: None declared

DOI: 10.1136/annrheumdis-2019-eular.4772

\section{SAT0365 SECULAR CHANGES IN PSORIATIC ARTHRITIS PATIENTS STARTING FIRST COURSE OF BIOLOGIC THERAPIES - INFLAMMATORY HALLMARKS OF LESSER PROMINENCE: A NORDIC POPULATION- BASED COHORT STUDY}

${ }^{1,2}$ Rebekka L. Hansen, Tanja Schjødt Jørgensen ${ }^{1,2}$, Lene Dreyer ${ }^{1,2}$, Björn Gudbjornsson ${ }^{3}$, Johan Askling ${ }^{4}$, Merete L. Hetland ${ }^{1}$, Bente Glintborg ${ }^{1}$, Daniela DI Giuseppe ${ }^{4}$, Lennart T.H. Jacobsson ${ }^{4}$, Tore K. Kvien ${ }^{5}$, Dan Nordström ${ }^{6}$, Kalle Aaltonen ${ }^{6}$, Sella Aarrestad Provan ${ }^{5}$, Eirik Kristianslund ${ }^{5}$, Johan K. Wallman ${ }^{4}$, Thorvardur Jon Love ${ }^{3}$, Lars Erik Kristensen ${ }^{1,2}$. ${ }^{1}$ On behalf of the DANBIO registry, Copenhagen, Denmark; ${ }^{2}$ Parker Institute, Copenhagen, Denmark; ${ }^{3}$ On behalf of the ICEBIO registry, Reykjavik, Iceland; ${ }^{4}$ On behalf of the SRQ registry, Stockholm, Sweden; ${ }^{5}$ On behalf of the NOR-DMARD registry, Oslo, Norway; ${ }^{6}$ On behalf of the ROB-FIN registry, Helsinki, Finland

Background: Psoriatic arthritis (PsA) is a chronic inflammatory disorder associated with skin and joint manifestations, several extra-articular symptoms, various comorbidities, and disability[1,2]. The emergence of tumour necrosis factor inhibitor (TNFi) therapy has dramatically changed the course of disease. Additional TNFi therapies (certolizumab pegol and golimumab) have been marketed, and recently ustekinumab has become available for PsA.

Objectives: To assess the use of biological agents (bDMARDs) in PsA from 2006-2017, using data from the Nordic Rheumatology registers.

Methods: Based on data from the registers DANBIO, ICEBIO, NORDMARD, ROB-FIN, and SRQ, PsA patients initiating bDMARDs or biosimilars, as a first or subsequent biological therapy were identified. Adalimumab, etanercept and infliximab were grouped as 1 st generation therapies; certolizumab pegol, golimumab were grouped as $2 n d$ generation therapies and biosimilar treatments were grouped. Treatments with ustekinumab were also identified. Pearson correlation tests were calculated and $p>0.05$ were considered significant. $R^{2} \approx 1$ showed a strong correlation between the baseline characteristics.

Results: A total of 18,089 treatment initiations were identified (DANBIO 4,361, ICEBIO 449, NOR-DMARD 1,948, ROB-FIN 1,069, SRQ 10,262). $53.68 \%$ of the patients were female. Overall, 6,198 patients initiated 1 st generation therapies, 1,447 2nd generation therapies, 1,353 biosimilars and 52 ustekinumab, as their first course of bDMARDs. Initiations of second or subsequent bDMARDs were 4,560, 1,630, 2,176 and 376 patients, respectively. The total of first course bDMARD initiators increased significantly from 2006-2017 $(p<0.001)$, similar to patients switching therapy $(p<0.001)$. Ustekinumab was primarily used as a second or subsequent bDMARD. The figure shows the secular trends of baseline characteristics collected from the Nordic countries with the subcategories of CRP, disease duration, HAQ score, VAS patient pain, swollen joint count and tender joint count from 2006-2017. All five countries showed trends of decreasing CRP, SJC and TJC values over time. Other parameters only showed slight or no correlation. 